\title{
Vulnerabilidade institucional do setor saúde a desastres: perspectiva dos profissionais e gestores de Nova Friburgo
}

\author{
Institutional vulnerability of the health sector to disasters: \\ perspective of professionals and managers from Nova Friburgo \\ Isadora Vida de Mefano e Silva', Carlos Machado de Freitas', Leonardo Esteves de Freitas ${ }^{\mathbf{1}}$
}

DOI: $10.1590 / 0103-11042020 E 213$

RESUMO Alguns países têm perdido até $50 \%$ da sua capacidade hospitalar em decorrência de eventos extremos. Aproximadamente 67\% das instalações de saúde da América Latina e do Caribe localizam-se em áreas propensas a desastres. Considerando as condições de vulnerabilidade, esses desastres constituem uma ameaça à saúde pública. Se o próprio setor saúde é vulnerável, um determinado evento pode afetar a vida de mais pessoas, tanto trabalhadores e usuários que estão nos estabelecimentos de saúde no momento, se estes estão localizados em áreas de risco, como comprometendo a sua capacidade de resposta aos impactos desse evento na saúde da população. Boa parte dos estudos sobre desastres são realizados ouvindo a população, suas percepções e representações sociais. Entretanto, poucos estudos foram feitos sobre a percepção dos trabalhadores da saúde nesses desastres. Por meio de entrevistas com profissionais de saúde e gestores no município de Nova Friburgo, foi identificado que, além da vulnerabilidade das infraestruturas de saúde em áreas de risco, o setor também se torna vulnerável pela falta de preparação e de participação na elaboração dos planos municipais de gestão de risco, bem como pela falta de participação dos profissionais da ponta e das comunidades na elaboração dos planos do próprio setor.

PALAVRAS-CHAVE Desastres. Vulnerabilidade a desastres. Risco. Redução do dano.

\begin{abstract}
Some countries have lost up to $50 \%$ of their hospital capacity due to extreme events. Approximately 67\% of Latin American and Caribbean health facilities are located in disaster-prone areas. Given the conditions of vulnerability, these disasters pose a threat to public health. If the health sector itself is vulnerable, a particular event could affect the lives of more people, both workers and users who are in health facilities at that time, if they are located in risk areas, such as compromising their ability to respond to impacts of this event in the health of the population. Most disaster studies are conducted by listening to the population, their perceptions and social representations. However, few studies have been done on the perception of health workers in such disasters. Through interviews with health professionals and managers in the municipality of Nova Friburgo, it was identified that, in addition to the vulnerability of health infrastructure in risk areas, the sector also becomes vulnerable due to the lack of preparation and participation in the elaboration of municipal plans for health risk management, as well as the lack of participation of senior professionals and communities in the elaboration of the sector's own plans.
\end{abstract}

KEYWORDS Disasters. Disaster vulnerability. Risk. Harm reduction.

1Fundação Oswaldo Cruz (Fiocruz) - Rio de Janeiro (RJ), Brasil.

isadoramefano@gmail.com 


\section{Introdução}

Nas últimas décadas, o tema dos desastres tem-se tornado cada vez mais relevante nas agendas intergovernamentais globais. Dos acordos firmados pós-2015 pelos países-membros das Nações Unidas, o Marco de Sendai para Redução do Risco de Desastres ${ }^{\mathbf{1}}$, os Objetivos de Desenvolvimento Sustentável (ODS) ${ }^{2}$ e o Acordo Climático de Paris ${ }^{3}$ possuem metas e indicadores transversais. É consenso entre os marcos supracitados que as mudanças climáticas e os desastres associados ao clima impactam diretamente as condições de saúde, evidenciando a importância da participação do setor nas ações intersetoriais para Redução do Risco de Desastres (RRD) e adaptação às mudanças climáticas, buscando alcançar os ODS4.

Alguns países têm perdido até $50 \%$ da sua capacidade hospitalar em decorrência de eventos extremos. Aproximadamente 67\% das instalações de saúde da América Latina e do Caribe localizam-se em áreas propensas a desastres ${ }^{5}$. Instalações de saúde são edificações com uso e finalidade bem definidas. Em uma situação de desastre, elas são uma referência para a comunidade afetada. Uma instalação com sua capacidade de atendimento comprometida significa um recurso a menos, justamente quando a população mais necessita, constituindo-se em uma vulnerabilidade no sistema de saúde, que potencializa a vulnerabilidade da população afetada ${ }^{6}$.

Os acordos firmados pós-2015 orientam ações definidas em escala global e que, no fim da linha, serão concretizadas, ou não, em escala local. Esta última escala, portanto, é uma escala privilegiada para entender os principais impactos dos desastres na saúde e as alternativas reais do setor para lidar com esse tipo de evento. O objetivo deste artigo, portanto, é apresentar um estudo de caso, buscando, por meio da análise de depoimentos de profissionais de saúde, identificar as principais vulnerabilidades do setor saúde, bem como as políticas de redução de risco adotadas, e sua efetividade no território. Boa parte dos estudos sobre desastres são realizados ouvindo a população, suas percepções e representações sociais, entretanto, poucos estudos foram feitos sobre a percepção dos trabalhadores da saúde nesses desastres.

O recorte do estudo se dá no município de Nova Friburgo, onde, em 2011, ocorreu um dos maiores desastres já registrados no Brasil. Nesse evento, fortes chuvas provocaram enchentes e deslizamentos que atingiram áreas rurais e urbanas, comunidades de baixo e de alto poder aquisitivo, algumas ficando totalmente isoladas, destruindo prédios e habitações, infraestrutura pública ( 73 pontes destruídas, e as principais vias de acesso foram totalmente ou parcialmente afetadas), estabelecimentos de saúde e escolas, comprometendo principalmente os serviços de abastecimento de água, energia elétrica e telefonia fixa ${ }^{7}$.

De acordo com relatório do Ministério da Saúde, no ano de 2011, 92,3\% dos estabelecimentos do município estavam em áreas de risco de inundação e/ou deslizamento, foram afetados, ou estavam funcionando de maneira precária ${ }^{8}$. Sete anos depois do desastre, os estabelecimentos de saúde do município permanecem nas mesmas áreas de risco ${ }^{6}$.

\section{Vulnerabilidade do setor saúde e desastres}

Para que um desastre ocorra, é preciso mais do que um evento extremo que se constitua como uma ameaça. Sob a perspectiva das ciências sociais, dá-se ênfase aos processos como a base através da qual as ameaças se transformam em desastres. Esses processos estão relacionados com a construção, ao longo do tempo, dentro da dinâmica de sistemas sociais, de infraestruturas e grupos populacionais expostos, em condições de vulnerabilidade, com insuficiente capacidade de responder e se restabelecer diante de uma situação de desastre? .

Considerando as condições de vulnerabilidade, os desastres constituem uma ameaça à saúde pública. Se o próprio setor saúde é 
vulnerável, um determinado evento pode afetar a vida de mais pessoas, tanto trabalhadores e usuários que estão nos estabelecimentos de saúde no momento, se estes estão localizados em áreas de risco, como comprometendo a sua capacidade de resposta aos impactos desse evento na saúde da população. Os impactos e problemas de saúde decorrentes dos desastres, por sua vez, sobrepõem-se aos problemas e necessidades crônicas e cotidianas, podendo comprometer em longo prazo a capacidade de resposta de um sistema de saúde.

\section{Área do estudo}

O município de Nova Friburgo está localizado na Região Serrana do estado Rio de Janeiro, Brasil, mais especificamente na Serra dos Órgãos. Trata-se de uma formação geomorfológica característica, apresentando vales alongados e relevos acidentados. É uma região de clima predominantemente tropical de altitude, com temperatura média de $16^{\circ} \mathrm{C}$ e precipitação média anual de cerca de 2.500 $\mathrm{mm}$ nas áreas mais altas ${ }^{\mathbf{1 0}}$. Suas condições climáticas, associadas ao relevo serrano, ocasionam no município, e em seu entorno, as famosas chuvas de verão $0^{10}$.

De acordo com o levantamento realizado pela secretaria de saúde de Nova Friburgo, o município apresenta um histórico de desastres bem significativo, com intervalos não muito longos entre um e outro (quadro 1), o que nos faz pensar que eventos extremos constituem a rotina dessa região e que, mantidas as mesmas condições de vulnerabilidades estruturais, encontra-se um terreno propício para novos desastres.

Quadro 1. Histórico de desastres no município de Nova Friburgo

\begin{tabular}{|c|c|c|c|c|}
\hline Ano & Tipo do Evento & $\begin{array}{l}\text { Total de Área } \\
\text { atingida }\end{array}$ & $\begin{array}{l}\text { Óbitos diretamente } \\
\text { relacionados com o } \\
\text { evento }\end{array}$ & $\begin{array}{l}\text { Total de } \\
\text { Desabrigados }\end{array}$ \\
\hline 1979 & $\begin{array}{l}\text { Inundação de grandes proporções com prejuízos } \\
\text { materiais }\end{array}$ & Sem informação & 69 & Sem informação \\
\hline 1984 & $\begin{array}{l}\text { Inundação de média extensão com prejuízos } \\
\text { significativos }\end{array}$ & Sem informação & Sem registro & Sem informação \\
\hline 1986 & $\begin{array}{l}\text { Inundação de média extensão com prejuízos } \\
\text { significativos }\end{array}$ & Sem informação & Sem registro & Sem informação \\
\hline 1991 & $\begin{array}{l}\text { Inundação de média extensão com prejuízos } \\
\text { significativos }\end{array}$ & Sem informação & Sem registro & Sem informação \\
\hline 1996 & $\begin{array}{l}\text { Duas inundações de grandes proporções e preju- } \\
\text { ízos vultuosos }\end{array}$ & Sem informação & 04 & 26 \\
\hline 2005 & Duas inundações com prejuízos vultuosos & Sem informação & 01 & Sem informação \\
\hline 2007 & Inundações e deslizamentos & Sem informação & 11 & 1086 \\
\hline 2011 & $\begin{array}{l}\text { Maior desastre da história do Brasil com regis- } \\
\text { tros de inundações e deslizamentos }\end{array}$ & $\begin{array}{l}70 \% \text { da área do } \\
\text { município }\end{array}$ & 429 & 3.220 \\
\hline 2012 & $\begin{array}{l}\text { Janeiro - Cidade entra em alerta máximo } \\
\text { Novembro - Cidade entra em alerta máximo } \\
\text { com registro de deslizamento }\end{array}$ & Sem informação & Sem registro & Sem informação \\
\hline 2016 & $\begin{array}{l}\text { Janeiro - Queda de talude atingindo: } 1 \text { escola } \\
\text { municipal em sua totalidade, } 1 \text { posto de saúde } \\
\text { parcialmente, } 1 \text { residência em sua totalidade, } \\
\text { ferindo a moradora }\end{array}$ & Sem informação & Sem registro & Sem informação \\
\hline
\end{tabular}

Fonte: Prefeitura Municipal de Nova Friburgo"11. 


\section{Metodologia}

Para a coleta dos depoimentos, de acordo com a aprovação do Comitê de Ética em Pesquisa da Escola Nacional de Saúde Pública Sergio Arouca (Resolução $n^{\circ}$ 466/2012), por meio de um trabalho de campo, foram realizadas entrevistas semiestruturadas com profissionais de saúde e gestores do município. $\mathrm{O}$ trabalho de campo foi realizado no período do dia 17 ao dia 21 de setembro de 2018, no município de Nova Friburgo.

Os depoimentos resultantes das entrevistas foram sistematizados tendo como referência a técnica do Discurso do Sujeito Coletivo (DSC) ${ }^{\mathbf{1 2}}$, os quais revelaram representações sociais existentes entre os profissionais e gestores dos estabelecimentos entrevistados. Segundo Lefèvre e Lefèvre $^{12}$, os variados discursos coletivos que se pretende resgatar em uma pesquisa são reconstruídos a partir de Expressões-Chave (ECH). Estas são fragmentos de discursos individuais, trechos ou transcrições literais desses discursos, reveladoras da representação social do fenômeno em estudo. Para Lefèvre e Lefèvre ${ }^{12}$, todo discurso tem uma ou mais Ideias Centrais (IC). As IC são o sentido de cada discurso analisado e de cada conjunto homogêneo de ECH, não se constituindo em interpretações, mas em descrições desse sentido.
Para a realização dessas entrevistas, foram selecionados quatro estabelecimentos de saúde (quadro 2), seguindo os seguintes critérios:

1. Estarem mencionados no relatório da sala de situação do Ministério da Saúde;

2. Estarem em área de suscetibilidade à inundação ou deslizamento;

3. Nível de complexidade do atendimento;

As informações secundárias sobre os estabelecimentos de saúde foram coletadas no site do Cadastro Nacional de Estabelecimentos de Saúde (CNES) e no site da Prefeitura Municipal de Nova Friburgo. As informações sobre a suscetibilidade de inundações foram coletadas no site da Companhia de Pesquisa de Recursos Minerais (CPRM - Serviço Geológico do Brasil). As informações sobre suscetibilidade a deslizamentos foram produzidas pelo Departamento de Recursos Minerais do Estado do Rio de Janeiro (DRM-RJ - Serviço Geológico do Rio de Janeiro), entretanto, elas não estão disponíveis em modo público, tendo sido fornecidas pela Secretaria de Meio Ambiente do Município de Nova Friburgo.

Quadro 2. Estabelecimentos selecionados para realização das entrevistas semiestruturadas

\begin{tabular}{|c|c|c|c|c|}
\hline Estabelecimento & $\begin{array}{l}\text { Nível de comple- } \\
\text { xidade de atendi- } \\
\text { mento }\end{array}$ & $\begin{array}{l}\text { Suscetibilidade } \\
\text { a inundação }\end{array}$ & $\begin{array}{l}\text { Suscetibilidade a } \\
\text { deslizamento }\end{array}$ & Observações \\
\hline $\begin{array}{l}\text { Hospital Municipal } \\
\text { Raul Sertã (referência } \\
\text { do município) }\end{array}$ & $\begin{array}{l}\text { Hosp. Alta/ } \\
\text { Hosp. Média/ } \\
\text { Amb. Alta/ } \\
\text { Amb. Média/ } \\
\text { Amb. Básica }\end{array}$ & Média & Não Mapeado & $\begin{array}{l}\text { Estabelecimento localizado em área de risco. Inundações são } \\
\text { recorrentes no local. Proximidade de rodovia de escoamento } \\
\text { de polo cimenteiro - risco de acidente com carga perigosa. } \\
\text { Remanejamento recomendado. }\end{array}$ \\
\hline $\begin{array}{l}\text { Hospital particular } \\
\text { São Lucas (acolhe } \\
\text { leitos do SUS) }\end{array}$ & $\begin{array}{l}\text { Hosp. Intern./ } \\
\text { Amb. Alta/ } \\
\text { Amb. Média }\end{array}$ & Não Mapeado & Alta & $\begin{array}{l}\text { Apesar de não constar neste relatório, notícias de jornal infor- } \\
\text { mavam que o estabelecimento foi gravemente afetado por um } \\
\text { rolamento de bloco no desastre de } 2011 .\end{array}$ \\
\hline UPA 24 Horas & $\begin{array}{l}\text { Amb. Média/ } \\
\text { Amb. Básica }\end{array}$ & Alta & Não Mapeado & $\begin{array}{l}\text { Estabelecimento em funcionamento precário. Carência de pes- } \\
\text { soal de enfermagem, médico de reforço e pessoal de limpeza. }\end{array}$ \\
\hline $\begin{array}{l}\text { Unidade Básica de } \\
\text { Saúde de São Geraldo }\end{array}$ & $\begin{array}{l}\text { Amb. Média/ Amb. } \\
\text { Básica }\end{array}$ & Não Mapeado & Alta & Estabelecimento moderadamente atingido por inundação. \\
\hline
\end{tabular}

Fonte: Elaboração própria. 
Para a seleção dos profissionais a serem entrevistados, foi realizado previamente um levantamento dos profissionais dos estabelecimentos selecionados, tentando cruzar os que já trabalhavam no estabelecimento quando aconteceu o desastre de 2011 com os que trabalhavam na época da realização das entrevistas. Esse levantamento foi realizado com informações de recursos humanos disponíveis no CNES. Tentou-se selecionar nomes de diferentes categorias profissionais, entre elas, administrativa, médica, enfermagem e agente comunitário de saúde, para tentar, posteriormente, um agendamento prévio para as entrevistas. Entretanto, no momento do campo, as entrevistas foram realizadas de acordo com a disponibilidade, indicação e anseio de participar por parte dos entrevistados. Foi empregada a técnica de entrevista aberta com o uso de um gravador de áudio, estabelecendo-se um diálogo informal com o entrevistado, tendo por base um roteiro semiestruturado (quadro 3). Elas foram realizadas nos próprios estabelecimentos, normalmente em salas que foram disponibilizadas para que não houvesse muito barulho. Foram realizadas 10 entrevistas com profissionais dos estabelecimentos selecionados, com uma média de 18 minutos por entrevista. Além dos profissionais, também foram entrevistados um gestor da secretaria municipal de saúde e um gestor da defesa civil municipal.

Quadro 3. Roteiros de entrevista com profissionais de saúde e gestores da saúde e Defesa Civil do município de Nova Friburgo

Roteiro para entrevista semiestruturada com os profissionais de saúde das unidades selecionadas para o estudo

\begin{tabular}{ll}
\hline Tema & Pergunta \\
\hline Sobre o entrevistado & $\begin{array}{l}\text { Nome; Sexo, Idade, Tempo que reside no município; Categoria profissional na unidade de saúde; Tempo de trabalho na } \\
\text { unidade de saúde }\end{array}$
\end{tabular}

Sobre o evento de 2011 Você já trabalhava nesta unidade de saúde quando ocorreu o evento de 2011?; Esta unidade de saúde foi afetada no evento de 2011? Como foi?; Você atuou no atendimento das vítimas do evento? Como?; Você considera que a unidade de saúde estava preparada para acolher as vítimas do evento? Se não, o que você acha que poderia ter sido diferente?

Sobre a gestão de risco

$$
\begin{aligned}
& \text { Você tem conhecimento de algum plano de contingência elaborado pelo setor saúde sobre como agir caso ocorram } \\
& \text { novos eventos?; Você participou de algum treinamento para melhor responder caso ocorram novos eventos? Como } \\
& \text { foi?; Você considera que a unidade de saúde está mais bem estruturada para receber as vítimas de um possível evento, } \\
& \text { do que estava em } 2011 \text { ? Por quê?; Como você acha que deve ser o papel do Setor Saúde na gestão de risco de desas- } \\
& \text { tres hidrológicos no município? }
\end{aligned}
$$

Roteiro para entrevista semiestruturada com os gestores da secretaria e saúde e defesa civil do município de Nova Friburgo

\begin{tabular}{ll} 
Tema & Pergunta \\
\hline Sobre o entrevistado
\end{tabular}

Sobre o entrevistado

Nome; Sexo; Idade; Tempo que reside no município; Profissão; Cargo; Trajetória profissional

O município de Nova Friburgo apresenta alta suscetibilidade a inundações e movimentos de massa, segundo o mapeamento realizado pelo Serviço Geológico do Brasil (mostrar mapa elaborado pela autora). Observando o histórico de ocorrência de desastres no município, pode-se notar que esse tipo de ocorrência não é uma novidade. Você considera que, diante desses fatores que permitem certa previsibilidade para a ocorrência de desastres, o poder público tem se organizado para que esteja mais bem preparado em casos desse tipo de ocorrência? Se sim, como? Se não, por quê?

Considerando que o desastre ocorrido em 2011 foi um marco para a elaboração da Política Nacional de Proteção e Defesa Civil, você acha que a gestão de risco de desastres no município evoluiu após a ocorrência deste desastre? Se sim, de que maneira? Se não, por quê?

Você considera que a gestão de risco de desastres no município acontece de forma intersetorial?

Você considera que a população e os funcionários da ponta são peças-chave para esta gestão? Se sim, sua participação acontece de formas eficaz? Se não, por quê?

Fonte: Elaboração própria. 
Por questões de privacidade, os profissionais e gestores foram descritos fazendo referência ao estabelecimento ou secretaria no qual trabalhavam. Sendo assim, temos as seguintes descrições: UP1 e UP2 (profissionais da Unidade de Pronto Atendimento - UPA 24 horas de Nova Friburgo); RS1, RS2, RS3 e RS4 (profissionais do Hospital Municipal Raul Sertã); SL1 e SL2 (profissionais do Hospital São Lucas); SG1 e SG2 (Unidade Básica de Saúde - UBS de São Geraldo); GS (Gestor da Secretaria de Saúde); GDC (Gestor da Defesa Civil). Durante a construção dos DSC, foi necessária a inserção de algumas palavras e preposições com o objetivo de tornar os discursos mais coerentes e com sentido.

\section{Resultados e discussões}

Seguindo o caminho metodológico elucidado, foram construídos 12 DSC, que serão apresentados em grupos por temáticas que foram surgindo de acordo com a ordem das perguntas do roteiro da entrevista.

\section{Desastres recorrentes, sem preparação, afetando os estabelecimentos de saúde}

DSC 1 - O estabelecimento de saúde foi afetado.

(UP1) [estabelecimentos de saúde foram] bastante afetados no momento que aconteceu, né. A água aqui dentro dessa unidade chegou mais ou menos uns 40 a 50 centímetros. (UP2) [...] ficou sem luz, sem energia, como a cidade toda ficou. (RS1) A emergência alagou toda, a cozinha, o laboratório, raio- $X$, as salas ali de baixo dos consultórios, que é a parte de gesso, o ambulatório também. (RS2) O pronto socorro encheu bem também. (RS3) [...] Pelo esgoto a água veio e interditou o primeiro andar quase todo [...] tudo que tem no primeiro andar, no subsolo, ali afetou tudo. (RS4) Então foi tudo afetado em 2011. (SG2) Na realidade entrou água, né, na nossa unidade, (SG2) a água veio praticamente até o teto.
DSC 2 - Falta de preparo para lidar com uma situação daquela magnitude.

(UP1) Nunca tinha acontecido aquilo, e a gente não sabia como lidar com aquele tipo de situação que estava acontecendo naquele momento, entendeu? (UP2) Acho que também foi tão inesperado que pegou todo mundo de surpresa. Mas preparada acho que não tava não. (SG1) E na época da tragédia a gente não foi muito bem orientado, né. (SL1) (até porque), acho que ninguém nunca está preparado para isso, né. (SG2) Todo mundo de cabeça quente, sem saber aonde, né... porque assim, foi uma coisa ímpar! Ninguém esperava um desastre naquela magnitude que a gente teve na época, né. Dentro daquilo que nós sabíamos, a gente fez, né. O que poderia ter sido feito? Posso muito sincera? Não sei, porque foi uma coisa que pegou todo mundo de surpresa. (UP1) Principalmente a parte do poder público. Naquele momento eu acho que nenhuma unidade aqui dessa região nossa, todos os municípios que foi atingidos, não estava preparado para essa situação.

DSC 3 - O evento de 2011 não foi o único evento marcante no município.

(RS3) E ao contrário, não sei se vocês sabem... já é a segunda grande tragédia de Friburgo, né. Da outra que teve, eu estava aqui... não lembro quando que foi, se foi em 76, ou em 78... foi da década de 70. Eu já estava em Friburgo, só que eu era criança. Já houve isso e não sei como foi. (SG2) [Além desses], em 2007 São Geraldo ficou preso uma semana, e não foi enchente, né. Choveu muito, aí caiu uma barreira próximo dessa ponte branca, onde morreram em torno de 7 pessoas, né... nada se fez. Depois a gente teve, bem antes de 2007, 1990, ou 91, mais ou menos, que choveu bastante também... abriu-se várias crateras nos loteamentos, pessoal ficou ilhado de novo, deram uma guaribada e nada foi feito. Então, assim, a gente já perdeu essa esperança de que se vá fazer algo pelo bairro. Então são coisas que a gente espera, e não é só 2011 não, a gente espera isso desde 76, que teve o primeiro que a gente lembra. 
Os discursos 1, 2 e 3 mostram que, apesar de haver precedentes que já exigiam um planejamento do sistema de saúde voltado para a gestão de risco, o corpo de profissionais dos estabelecimentos não esperava que ocorresse um evento como aquele, o que demonstra uma situação de despreparo do setor. Esse despreparo se constitui uma vulnerabilidade que compromete sua capacidade de resposta, justamente quando a população mais necessita $^{6}$. Uma maior participação do setor saúde nos planos de preparação e resposta municipais estaria em consonância com o Marco de Sendai, à medida em que este reconhece a necessidade de trabalhar no âmbito intersetorial. Da mesma forma, também exige que, intrassetorialmente, o setor Saúde estivesse mais organizado no sentido de avançar na agenda de RRD, para assim participar de maneira mais efetiva.

Os princípios de Bangkok ${ }^{\mathbf{1 3}}$, formulados para auxiliar os países na implementação dos aspectos da saúde do Marco de Sendai, ditam em seu princípio número um sobre promover a integração sistemática da saúde nas políticas e planos nacionais e subnacionais para RRD, e incluem programas de gestão de risco de desastres e emergências nas estratégias de saúde em nível nacional e subnacional.

DSC 4 - Estabelecimentos de saúde vulneráveis; profissionais de saúde vulneráveis.

(RS3) [...] porque nós também fomos atingidos, a unidade foi atingida, entendeu? (RS1) tinha a nossa família que as pessoas não sabiam onde é que tavam, o que que tava acontecendo, eu mesma não sabia o que que tava acontecendo com a minha, entendeu? Eu vim pra cá e fiquei aqui, só fui descobrir depois que tava tudo bem, graças a deus. Que eu não tinha perdido nada e tal, mas quem tava aqui, cada vez que a gente ouvia alguma coisa 'ó caiu em algum lugar uma casa...' a gente pensava 'ihh, peraí... funcionário tal mora lá, ai meu deus, será que foi com ele?'. Foi bem pesado... (SL2) eu sou morador de bom jardim e eu fiquei sem poder ir embora pra minha casa, né. Amanheceu o dia, que eu olhei aquilo tudo ao redor como estava, pensando como estaria a casa da minha mãe, como a minha mãe tivesse pensando, aí você vai e começa a desequilibrar em algumas coisas, mas depois você vai e recupera de novo. (SG2) eu peguei uma bactéria na boca, né, em 2011. Aí eu fiz uma cirurgia... não, eu fiz duas cirurgias na boca, já. Graças a Deus, hoje eu já estou bem, mas gastei bastante. (RS2) além disso, a parte emocional, né, que fica muito abalada... nós ficamos, eu fiquei... até uns tempos atrás, eu lembrava e chorava, entendeu?

Da mesma forma que é discutido por Debarati Guha-Sapir ${ }^{14}$, é importante considerar, em casos de desastres, que, muitas vezes, as equipes de saúde possuem mesmo este duplo papel, de serem, ao mesmo tempo, vítimas e responsáveis pelo atendimento de pacientes. O acesso ao hospital, a segurança própria e a falta de informação sobre seus familiares são fatores que influenciam sua performance em ambos os níveis, pessoal e profissional, o que também tem sua influência no comprometimento da capacidade de resposta em situações de desastre. Entre esses profissionais, a fé e o comprometimento com o atendimento dos pacientes são aspectos emocionais que fortalecem as equipes de saúde.

DSC 5 - A assimetria nas políticas de prevenção de riscos futuros - deslocam-se as pessoas, mas não a infraestrutura pública.

(RS3) A água, conforme caiu barreira daqui [atrás do hospital], e a enxurrada veio daqui, com o rio cheio daqui, então veio uma com a outra, porque a gente está no meio de duas vias, né. Então veio dos dois lados. Porque é difícil, sem ver é difícil. Porque aqui tem uma montanha, e lá debaixo já é o rio, então veio dos dois lados. (SG2) Aí você pega assim, a nossa escola aqui, ela foi feita numa área de alagamento, em cima do aterro. Aí eu pergunto, a comunidade foi consultada se queria a escola ali? O posto também, ele fica numa área de risco, né. O rio é aqui do lado, quando ele encheu foi água para tudo aqui. (SG1) Até mesmo porque, aqui acho que é meio que um brejo, né. Aí é complicado. (SG2) E até onde eu sei a prefeitura até hoje não tomou, 
uma posição de tirar o posto daqui. Até hoje nada disso. Sendo que a maioria dos moradores, nem os próprios funcionários, sabem que isso aqui é uma área de risco. Então eu não sei, esse é o meu ponto de vista. Eu acho que pra eles não seria viável falar que nós estamos numa área de risco, entendeu? Sendo que muitas pessoas queriam voltar para as áreas de risco. Se não desapropriasse, elas estariam ali. Por quê? Nasceu ali, foi criado ali, gosta do lugar, e assim sucessivamente... Então, São Geraldo não fica longe disso. Eu digo assim, Alto do Floresta também não fica longe disso... As pessoas que foram nascidas e criadas ali, elas não querem perder a sua identidade. E com essa questão de 2011, todo mundo perdeu.

Uma das ações da Defesa Civil após o desastre de 2011 foi, utilizando como base as cartas de suscetibilidade a inundações e deslizamentos (DRM e CPRM) e, principalmente, o estudo elaborado pelo Inea para as áreas situadas às margens dos rios, remover as populações residentes em áreas de risco para o Terra Nova, empreendimento habitacional construído no âmbito do programa Minha Casa Minha Vida. Entretanto, as ferramentas utilizadas para retirar os moradores de suas casas em áreas de risco não foram utilizadas da mesma forma para tirar os estabelecimentos das áreas de risco. A combinação dessa primeira ação seguida de uma inação em relação aos estabelecimentos de saúde e escolas só acentuam a vulnerabilidade social da população ${ }^{6}$.

A vulnerabilidade institucional permanece a mesma, pois os estabelecimentos continuam nos mesmos lugares. Já a população, ao ser removida de suas casas, perde a identidade e o laço com a vizinhança que, muitas vezes, é o primeiro referencial de ajuda em uma situação de desastres. Segundo o Marco de Sendai, a pobreza e a desigualdade são os principais determinantes da exposição de uma família, comunidade e sociedade a riscos.

A vulnerabilidade, assim como pobreza e desigualdade, é variável em uma cidade. Normalmente, os mais pobres e desprivilegiados estão desproporcionalmente em risco devido a atributos locais, acesso a recursos e desigualdades socioespaciais. Quando a urbanização não é planejada, ou nos casos em que a urbanização é planejada atendendo a interesses privados e especulação imobiliária, em vez de privilegiar o interesse público e coletivo, os moradores mais pobres podem se estabelecer em áreas propensas a riscos, e sua subsequente mudança para zonas 'mais seguras', sem a devida consulta, pode, de fato, torná-los vulneráveis de outras maneiras, removendo importantes fontes de meios de subsistência e redes sociais. Além disso, há também a questão do deslocamento entre a residência e o trabalho, ou entre a residência e serviços de saúde. Usualmente, as novas áreas habitacionais estão localizadas longe das atividades dos antigos moradores de áreas de risco, o que requer deles mais dinheiro e mais tempo para o transporte.

De fato, essa situação foi observada para os moradores do Terra Nova ${ }^{\mathbf{1 5}}$. Isso pode reduzir a capacidade dos moradores de lidar com futuros riscos e desastres diários, bem como comprometer os avanços nos indicadores dos ODS ${ }^{\mathbf{1 6}}$.

DSC 6 - A invisibilidade dos impactos na saúde mental.

(SG2) De 2011 para cá, a gente percebe que... assim, nós temos um alto índice de pacientes depressivos, e as pessoas ainda estão com muito medo. Quando chove, tipo assim, o temporal que deu no sábado, aí domingo deu outro, segunda deu outro... então, quando começa a trovejar, todo mundo já fica bem alarmado, né. (UP2) A gente percebe muitos problemas psicológicos, né. Teve muita gente que perdeu família inteira, filho, marido, aí aumentou bastante. (SG2) Foi uma pena que a equipe que veio ajudar foi embora, porque a gente precisava que os psicólogos que estavam aqui na época fizessem o acompanhamento da comunidade, então a gente ficou capenga, porque, por exemplo, hoje aqui a gente só tem um psicólogo. Mas eles não se preocupam. Porque houve aquele movimento, né, todo em 2011, e de 2012 para cá, deu, assim, uma pausa, assim, e toda vez que a 
gente tenta falar sobre o assunto em determinadas reuniões, há um corte violento ali, entendeu. (RS1) E o setor saúde, ele tem responsabilidade o tempo todo, e numa situação dessa, ele vai ter mais, né.. ele tem que atender o retorno, ele tem que ver o que que tá acontecendo depois.

Usando como referência Bankoff 9 e Freitas et al. ${ }^{17}$, pensando sob a perspectiva das ciências sociais, os desastres devem ser entendidos enquanto processos; e seus impactos na saúde da população podem ocorrer tanto no momento imediato após a ocorrência de seu evento natural deflagrador como em períodos posteriores, de dias, meses, ou até mesmo anos depois da ocorrência do evento físico, como é o caso de transtornos sociais e comportamentais. O DSC 6 mostra que o setor saúde de Nova Friburgo ainda não está capacitado para atender a essas necessidades de saúde em longo prazo.

O Marco de Sendai, em sua prioridade três, têm como uma das ações-chave

[...] aumentar a resiliência dos sistemas nacionais de saúde, inclusive através da integração da gestão do risco de desastres no atendimento de saúde primário, secundário e terciário, especialmente em nível local; capacitar os profissionais da saúde para compreender o risco de desastres e aplicar e implementar abordagens de redução do risco de desastres no trabalho em saúde $[\ldots]^{\mathbf{1 ( 1 6 )}}$.

Entende-se que, no recorte de Nova Friburgo, essa prioridade ainda não está sendo posta em prática de maneira completa e efetiva.

\section{Perspectiva dos profissionais de saúde sobre as políticas institucionais de redução de risco de desastres no município}

DSC 7 - Não houve mudança estrutural; e, se ocorresse algo parecido, os impactos seriam os mesmos.
(RS1) Nós continuamos na mesma estrutura que nós tínhamos. Depois disso foi feito só o plano de contingência, né... a gente não teve nenhum treinamento absurdo não. Não tem como também mudar muito a estrutura do hospital. (RS2) Eu não vi muita mudança de estrutura, né, pra poder receber se acontecesse uma próxima vez não. (RS3) Infelizmente, nosso poder público... (RS4) Se acontecesse hoje ia ser a mesma coisa, inundar do mesmo jeito, porque não foi feito nenhuma obra diferente nesse sentido, as pessoas dizem que foi uma situação excepcional, porque foi uma chuva excepcional, né, [... e continua] tudo em obras, nada funcionando... (SG2) Então essa preparação a unidade não tem, precisa. Não houve essa capacitação, se eu falar para você, eu vou estar mentindo. Porque é aquilo que eu disse para vocês duas, até 2012 tinha algum buchicho, depois... nada.

DSC 8 - Não sabe de nenhum plano da secretaria de saúde, ou não tem certeza se existe, considera importante, e acha que deveria ter participação dos profissionais de saúde na sua etapa de elaboração.

(RS2) Você quer saber se depois disso teve alguma coisa? Não, não teve. E com certeza seria importante! Isso faz uma diferença enorme, né. Quando você tá preparado para receber alguma coisa, né, você consegue dar um suporte melhor pro paciente. (UP2) [Mas eu] não conheço [e eu acho que seria] muito importante ter um, e acho muito importante [a participação dos profissionais]. (SL2) [Seria importante até mesmo] para a segurança, né, de todos, seria uma coisa necessária. (SG1) [Na verdade] Eu não sei se tem algum firmado, mas eu acredito que sim, porque até mesmo que a gente teve que assinar algumas documentações, na gestão antiga. (SG2) Independente da gestão tem que ter. De preferência, que todo mundo saiba.

Os ODS têm como uma de suas metas, referente ao objetivo três, reforçar a capacidade de todos os países, particularmente os países em desenvolvimento, para o alerta precoce, redução de riscos e gerenciamento de riscos 
nacionais e globais de saúde. O DSC 7 mostra que, no município de Nova Friburgo, os planos da saúde voltados para a agenda de RRD ainda se constituem como uma ferramenta com pouca efetividade. Da mesma forma, esses planos não envolvem a participação dos profissionais em sua etapa de elaboração, tampouco são disseminados de forma que possam ser postos em prática.

Como já dizia Quarantelli18, é suposto que, se existe um plano de ação em casos de desastres, então o trabalho de emergência em crises será bem-sucedido; afinal, essa deveria ser a proposta de um plano. Infelizmente, entretanto, pesquisas mostram que isso está longe de ser uma realidade. Se o planejamento for muito segmentado ou segregado, em vez de envolver fatores sociais relevantes, ou se o planejamento exige atividades artificiais, muito destoantes das práticas cotidianas, a implementação desse tipo de planejamento será deficiente em situações reais de desastre.

Além disso, os princípios de Bangkok trazem, em uma de suas ações-chave, a necessidade de aprimorar a funcionalidade de segurança e a resiliência das infraestruturas e instalações críticas de saúde, realizando avaliações de segurança, fortalecendo a implementação da Iniciativa Hospitais Inteligentes e aplicando os princípios de 'Recuperar melhor' na recuperação e reconstrução, em coordenação com as comunidades. Nesse sentido, essa lacuna na gestão de risco de desastres compromete também o desenvolvimento sustentável, uma vez que, entre os ODS, o objetivo nove fala justamente sobre 'construir infraestruturas resilientes, promover a industrialização inclusiva e sustentável e fomentar a inovação'.

A inserção do setor saúde na gestão de risco de desastres e enfrentamento dos possíveis impactos na população

DSC 9 - Importância dos estabelecimentos para a população em situações de desastre.

(GS) todo mundo hoje entende a importância de uma unidade de saúde no momento de desastres, né... essa importância de referência pra comunidade, pra população. Aqui em Nova Friburgo, sobretudo as nossas unidades básicas de estratégia de saúde da família, são quase todas em área rural $e$ às vezes, é o único equipamento público que, junto com a escola, eles têm naquela comunidade. A unidade de saúde de Campo do Coelho, em 2011 foi fundamental, porque as pessoas corriam para lá. E não tinha ninguém para abrir! E aí alguém... eu não me lembro, acho que alguém arrombou... Agora não vou me lembrar direito se chegou algum servidor, ou alguém arrombou. E as pessoas que foram para ali, aí chegou uma médica que estava no Spá Maria Bonita, que é ali perto, começou a atender!! E as pessoas estavam indo para ali. Então com a unidade mesmo sendo pequenininha, foi fundamental naquele momento, era uma referência, as pessoas foram pra lá.

DSC 10 - Setor saúde é visto apenas como responsável pela resposta.

(GS) A questão da Saúde, também, quando você vai discutir desastre numa estrutura do município, isso fica muito mais focado na questão de obras e defesa civil, e o setor saúde é muito visto, na maioria das vezes, como resposta. Um setor só para atuar na resposta. Para Defesa Civil basta que na hora que aconteceu alguma coisa, o comandante liga e fala assim: 'prepara o hospital porque tem um deslizamento'. Mas e esse hospital, ele foi preparado para isso? É esse anterior que a Defesa Civil não se importa. E como é que deveria ser isso? Como é que se prepara isso? Como é que essa equipe tá preparada? Então, é sair um pouco dessa ideia de que a saúde é só resposta. Ela tem uma preparação, e também com esse destaque muito para o hospital, né. Quando, na realidade a gente sabe que tem unidade de saúde.

DSC 11 - Apesar de haver mais diálogo, a Defesa Civil ainda é protagonista.

(GS) Eu acho que hoje o setor saúde e a Defesa Civil, a gente conversa mais, tem um trânsito melhor. Mesmo assim eu acho que ainda o setor saúde não é chamado nas discussões mais amplas sobre questão de desastres no município. O setor saúde ainda não ocupa um lugar de protagonismo, 
de destaque nisso. Ele é muito chamado para ainda saber qual a infraestrutura que a gente tem para atuar, mas não ainda como um setor que pudesse auxiliar, junto e construir junto alternativas. Eu acho que a gente ainda não chegou nesse nível não. (GDC) O setor saúde tem um plano de contingência adequado ao plano de contingência nosso no município, que funciona em consonância, né, quando acontece um acidente desse tipo. Então, assim, há uma melhoria muito grande nessa questão de entrosamento de saúde e defesa civil.

Os princípios de Bangkok estabelecem como uma das ações-chave para a implementação dos aspectos da saúde do Marco de Sendai aumentar a participação de representantes do setor de saúde em comitês e plataformas multissetoriais de gerenciamento de riscos de desastres e emergências em todos os níveis. Os resultados dos DSC corroboram essa necessidade, mostrando a importância do setor saúde para a população em situações de desastres. Entretanto, o que podemos ver em âmbito nacional, ilustrado por meio do exemplo de Nova Friburgo, é que a Defesa Civil ainda ocupa um papel de protagonismo da agenda de RRD, deixando o setor saúde envolvido apenas nas ações de resposta.

DSC 12 - Dificuldades para a gestão de risco no âmbito do setor saúde.

(GS) Logo após 2011, eu acho que isso [construir unidades em áreas mais seguras] era uma preocupação maior. Eu observo que o espaço temporal entre 2011 e agora [7 anos] faz com que as pessoas já não coloquem isso como uma questão muito importante. E isso muito porque a gente tem uma dificuldade de gestão porque... eu tenho até que atualizar minha conta, mas eu acho que desde 2011 nós estamos no 13ㅇo ou 14을 secretário de saúde, então é muito complicado. É muito complicado você manter uma política se toda vez você tem que ter tempo para mostrar para o novo secretário o que que é o desastre, como é que a gente tem que se organizar... então fica bem complicado.

O DSC 12 indica questões políticas que dificultam o fortalecimento da participação do setor na agenda de RRD. Essa falta de preparo pode, por sua vez, prolongar o sofrimento da população em decorrência da falta de atenção aos problemas e necessidades de saúde que podem surgir, como já explicitado, tanto no momento imediato posterior à ocorrência do evento deflagrador do desastre como após semanas, meses, ou até mesmo anos depois.

Utilizando Bankoff ${ }^{9}$ e Nantenzon ${ }^{19}$ como referência, entende-se que essa instabilidade institucional está intimamente relacionada com a vulnerabilidade institucional, que, assim como o desastre, deve ser entendida como um processo. As características da estrutura institucional antecedentes a um desastre fazem parte dos eventos, processos e relações da estrutura social, econômica e política da sociedade afetada que configuram um cenário de risco. Sob essa perspectiva, em um cenário no qual em um intervalo de 7 anos a gestão da Saúde foi trocada 14 vezes (o que resulta um total de 2 gestores por ano) e, neste mesmo intervalo, os estabelecimentos de saúde permaneceram nas mesmas áreas de risco, com poucas medidas para melhorias estruturais, pode-se dizer que, na verdade, estabelecimentos de saúde em áreas de risco são a ponta de um iceberg de uma vulnerabilidade estrutural no município de Nova Friburgo.

Os princípios de Bangkok, referência para este trabalho, foram sistematizados para implementar os aspectos da saúde do Marco de Sendai. A figura 1 ilustra os sete princípios de Bangkok e os DSC construídos que se relacionam com cada uma dessas regras. 
Figura 1. Princípios de Bangkok associados aos DSC construídos na pesquisa

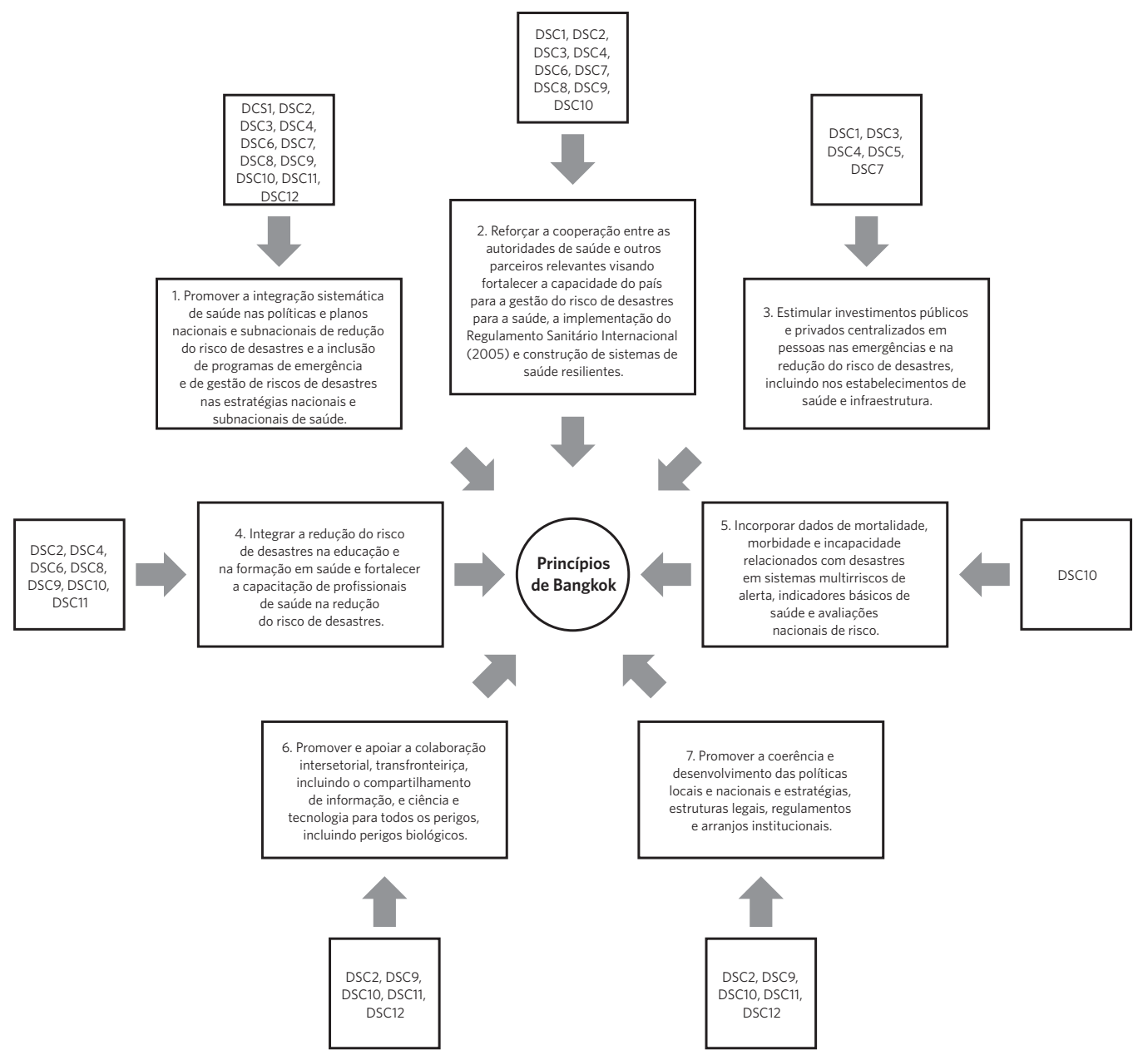

Fonte: Princípios de Bangkok, 2016.

\section{Considerações finais}

Por meio da análise das entrevistas, identificamos quatro temas que devem ser discutidos mais a fundo. No recorte estabelecido para o estudo, pudemos constatar que os desastres têm um grande impacto; e, a despeito de serem recorrentes, ainda não há uma preparação do setor saúde para lidar com isso. Como pudemos observar nos depoimentos, o setor saúde ainda não participa de forma efetiva dos planos municipais de gestão de risco; e, no âmbito intrassetorial, tampouco os planos são efetivos, disseminados e postos em prática por intermédio de capacitação e exercícios de treinamento. O Marco de Sendai reconhece a necessidade de haver planos, competências, orientação e coordenação intra e intersetorial, bem como a participação das partes interessadas, no caso, as populações afetadas e os trabalhadores dos setores envolvidos, para o fortalecimento da governança do risco de desastres para prevenção, mitigação, preparação, resposta, recuperação e reabilitação.

Outra questão importante identificada por meio dos depoimentos foi a invisibilidade dos impactos dos desastres na saúde mental. 
Em uma situação de desastres, o indicador de maior relevância acaba sendo a mortalidade, ou seja, o número de óbitos imediatos. Entretanto, deve haver uma maior preocupação com a saúde mental e com as doenças crônicas, para que o sofrimento decorrente do desastre não se prolongue temporalmente. A nova plataforma global de redução de riscos de desastres, Emergência sanitária e gerenciamento de riscos de desastres, lançada no ano de 2019, recomenda o desenvolvimento de estratégias e a implementação de ações para sistemas de saúde resilientes, incluindo programas voltados para a questão climática, e maior foco nos aspectos psicossociais da emergência em saúde e gerenciamento de riscos de desastres ${ }^{20}$.

A contraposição da política de remoção das populações de áreas de risco, a despeito de a infraestrutura dos estabelecimentos permanecer nos mesmos locais, foi outro ponto que chamou atenção dos autores. $\mathrm{O}$ Marco de Sendai, em sua prioridade número quatro, reconhece a importância dos laços de identidade e de vizinhança no fortalecimento da capacidade de resposta e resiliência das populações afetadas. Além do poder público acentuar a vulnerabilidade dessas pessoas ao deslocá-las de seus territórios, ainda acentua a vulnerabilidade institucional ao manter os estabelecimentos nos mesmos locais.

Em sua prioridade dois, o Marco de Sendai diz que a governança do risco de desastres tem grande importância para uma gestão de risco eficaz e eficiente. Pensando sob a perspectiva do setor saúde, a instabilidade política mencionada nos depoimentos também é um elemento a mais que enfraquece o gerenciamento do risco de desastres no município. De fato, dar continuidade a uma estratégia de fortalecimento da agenda de RRD intrassetorialmente, em um contexto de descontinuidade na gestão, é uma tarefa muito difícil'1.

O setor saúde do município de Nova Friburgo apresenta uma vulnerabilidade institucional a desastres que também é realidade em outros municípios e localidades do Brasil e do mundo. A identificação dessa vulnerabilidade permite elaborar metas e indicadores para adaptação dos marcos global às realidades locais, buscando sua implementação nas tomadas de decisão e formulação das políticas públicas.

\section{Colaboradores}

Silva IVM (0000-0001-9946-5147)*, Freitas CM (0000-0001-6626-9908)* e Freitas LE (0000-0003-4751-356)* contribuíram igualmente para a elaboração do manuscrito.
*Orcid (Open Researcher and Contributor ID).

\section{Referências}

1. United Nations Office for Disaster Risk Reduction. The Sendai Framework for Disaster Risk Reduction. Sendai: UNDRR; 2015.

2. Organização das Nações Unidas. Objetivos de Desenvolvimento Sustentável. Nova York: ONU; 2015.
3. Organização das Nações Unidas. Adoção do Acordo de Paris. Paris: ONU; 2015.

4. Maini R, Clarke L, Blanchard K, et al. The Sendai Framework for Disaster Risk Reduction and Its Indicators - Where Does Health Fit in?. Int. J Disaster Risk Sci. 2017; 8:150-155. 
5. Pan American Health Organization. Smart Hospitals Toolkit. Washington, D.C. PAHO; 2017.

6. Silva IVM. Vulnerabilidade Institucional do Setor Saúde a Desastres no Município de Nova Friburgo. [dissertação]. Rio de Janeiro: Escola Nacional de Saúde Pública Sérgio Arouca, Fundação Oswaldo Cruz; 2019. $142 \mathrm{p}$.

7. Freitas CM, Carvalho ML, Ximenes EF, et al. Vulnerabilidade socioambiental, redução de riscos de desastres e construção da resiliência - lições do terremoto no Haiti e das chuvas fortes na Região Serrana, Brasil. Ciênc. Saúde Colet. 2012; 17(6):1577-1586.

8. Brasil. Ministério da Saúde. Relatório final - Sala de situação para atendimento ao Rio de Janeiro. Rio de janeiro: MS; 2011.

9. Bankoff G. Time is of the essence: Disasters, Vulnerability and History. Inter. J. Mass Emerg. Disasters. 2004; 22(3):23-42.

10. Silva RP, Machado KM, Silva Junior GC, et al. Determinação de parâmetros físicos do solo em encosta sob influência de escorregamento translacional raso - Nova Friburgo, RJ. Rev. Bra. Geo. Eng. Amb. 2014; (4):51-64.

11. Prefeitura Municipal De Nova Friburgo. Plano de gestão de riscos em desastres. Nova Friburgo: PMNF; 2017.

12. Lefèvre F, Lefèvre AMC. Discurso do sujeito coletivo: um novo enfoque em pesquisa qualitativa (desdobramentos). Caxias do Sul, RS: EDUCS, 2003.

13. United Nations Office for Disaster Risk Reduction. Bangkok Principles for the implementation of the health aspects of the Sendai Framework for Disaster Risk Reduction 2015-2030. Bangkok: UNDRR; 2016.

14. Guha-Sapir D, Cuesta JG, Loenhout JAF, et al. The Impact of Typhoon Haiyan on Health Staff: A Qualitative Study in Two Hospitals in Eastern Visayas, The Philippines. Front. Pub. Health. 2011; 6(208):1-6.

15. Ervatti VS. Vulnerabilidade Sócio-Ambiental Pós-Desastre de Janeiro 2011: avaliação da política de reassentamento da população no município de Nova Friburgo (RJ). [dissertação]. Rio de Janeiro: Universidade Federal do Rio de Janeiro; 2018. 108 p.

16. United Nations Office for Disaster Risk Reduction. Words into Action Guidelines: Implementation guide for land use and urban planning. Geneva: UNDRR; 2019.

17. Freitas CM, Xavier DRS, Sena ARM, et al. Desastres naturais e saúde: uma análise da situação do Brasil. Ciênc. Saúde Colet. 2014; 19(9):3645-3656.

18. Quantelli EL. Disaster crisis management: a summary of research findings. J. maneg. Stud. 1988; (25):4.

19. Nantenzon CE. Riesgo, vulnerabilidad e incertidumbre. Desastres por inundaciones en Argentina. Buenos Aires: UBA; 1998.

20. World Health Organization. Health Emergency and Disaster Risk Management Framework Launched at the Global Platform for Disaster Risk Reduction. Geneva: WHO; 2019.

Recebido em 30/09/2019

Aprovado em 13/01/2020

Conflito de interesses: inexistente

Suporte financeiro: não houve 